\title{
Epidemiologia e ecologia das dermatofitoses na cidade de Fortaleza: o Trichophyton tonsurans como importante patógeno emergente da Tinea capitis
}

\author{
Epidemiology and ecology of dermatophytosis in fortaleza city: Trichophyton \\ tonsuransas an important emergent pathogen of Tinea capitis
}

\author{
Raimunda Sâmia Nogueira Brilhante ${ }^{14}$, Germana Costa Paixão1, Liliam Kécia Salvino1, \\ Maria José Nogueira Diógenes ${ }^{2}$, Silviane Praciano Bandeira ${ }^{1}$, Marcos Fábio Gadelha Rocha ${ }^{3}$, \\ João Bosco Feitosa dos Santos ${ }^{5}$ e José Júlio Costa Sidrim ${ }^{4}$
}

\begin{abstract}
Resumo As dermatofitoses são os distúrbios infecciosos de pele mais comuns do mundo. Na presente pesquisa foram avaliados 2.297 pacientes com lesões clínicas sugestivas de dermatofitoses das quais, 534 (23,2\%) mostraram-se positivas para dermatófitos. Destes, o T. rubrum foi a espécie mais prevalente $(49,6 \% ; p \leq 0,05)$, seguido por T. tonsurans $(34,4 \% ; p \leq 0,05), M$. canis (7\%) e T. mentagrophytes (6,2\%). Ao correlacionar-se as espécies isoladas com os respectivos sítios anatômicos, observou-se que o T. tonsurans foi o isolado mais freqüente nas lesões do couro cabeludo (73,9\%; $p \leq 0.01)$. Por outro lado, o T. rubrum foi o principal envolvido nas lesões do corpo $(72,8 \% ; p \leq 0,05)$. Portanto, nas infecções do couro cabeludo, observou-se o predomínio absoluto do T. tonsurans, dado este que se contrapõem, as estatísticas dos estados brasileiros da região Sudeste e Sul, bem como de outras regiões do mundo que correlacionam, ainda, o M. canis como sendo o microrganismo mais freqüentemente isolado nas Tinea capitis.

Palavras-chaves: Dermatofitose. Trichophyton tonsurans. Epidemiologia.
\end{abstract}

Abstract Dermatophytosis is the most common skin infectious disturbance in the world. In this research 2.297 patients were evaluated with suspected clinical lesions of dermatophytosis. It was observed that, $534(23.2 \%)$ patients tested positive for dermatophytes. T. rubrum was the most prevalent specie (49.6\%; $p \leq 0.05)$, followed by T. tonsurans $(34.4 \%)$, M. canis $(7 \%)$ and T. mentagrophytes (6.2\%). When the species isolated was correlated with the respective anatomical localization, it was observed that $\mathrm{T}$. tonsurans was the most frequent isolated in scalp lesions $(73,9 \% ; p \leq 0.01)$. On the other hand, T. rubrum was the main specie involved in body lesions (72.8\%; $p \leq 0.05)$. Therefore, in scalp infections it was observed that, there was an absolute prevalence of $\mathrm{T}$. tonsurans. This evidence is different from the statistical data collected in the southeast and south of Brazil, as well as from other areas of the world, which still show M. canis as the most frequent microorganism isolated in Tinea capitis.

Key-words: Dermatophytosis. Trichophyton tonsurans. Epidemiology.

\footnotetext{
1. Centro Especializado em Micologia Médica da Faculdade de Medicina da Universidade Federal do Ceará; 2. Serviço de Dermatologia da Faculdade de Medicina da Universidade Federal do Ceará; 3. Faculdade de Veterinária da Universidade Estadual do Ceará; 4. Laboratório de Micologia Médica do Centro de Dermatologia Dona Libânia da Secretaria de Saúde do Estado do Ceará; 5 . Mestrado de Saúde Pública, Universidade Estadual do Ceará, Fortaleza, CE.

Endereço para correspondência: Dr. José Júlio Costa Sidrim. R. Jabaquara 344, Castelão, 60861-200 Fortaleza, CE, Brasil.

Tel: 5585983 4974; fax: 55852951736

e-mail: cemm@ufc.br / sidrim@ufc.br

Recebido para publicação em 2/7/99.
} 
Os dermatófitos constituem o grupo de fungos mais freqüentemente isolados em laboratórios de micologia e ainda assim, descrições inconsistentes são assinaladas na literatura. Estudos epidemiológicos indicam que as dermatofitoses estão entre as doenças mais comuns do mundo, sendo consideradas o terceiro distúrbio de pele mais freqüente em crianças menores de 12 anos e o segundo em população adulta ${ }^{1323}$.

Vários motivos são aventados para explicar o aumento da incidência destas infecções nas últimas décadas, entre eles: o uso abusivo de antibióticos, drogas imunossupressoras e citostáticas, bem como o aparecimento de pacientes com SIDA, os quais constituem alvo para o desenvolvimento das dermatofitoses ${ }^{16} 29$. Aliado a esses fatores, os dermatófitos encontram nas condições de temperatura e umidade do clima tropical, o habitat ideal para sua disseminação ${ }^{17}$.

Por não figurarem entre as doenças de notificação obrigatória no Brasil, apenas estudos epidemiológicos fragmentados são relatados na literatura nacional, fazendo-se inquestionável a necessidade de pesquisas epidemiológicas, clínicas e laboratoriais que relatem dados reais, no tocante a incidência das dermatofitoses no nosso meio.

A distribuição geográfica dos dermatófitos mostra-se bastante variável; enquanto alguns são cosmopolitas, a distribuição de outros depende dos seguintes fatores: adaptação ao meio ambiente, deslocamentos humanos, convívio com animais domésticos, aspectos sócio-econômicos, sexo, idade e imunidade do hospedeiro, promovendo assim variações no espectro destes fungos, de região para região ${ }^{181832}$. Dessa forma, é importante o conhecimento das espécies dos dermatófitos de uma dada região, durante um período de tempo prolongado, permitindo estabelecer as espécies de ocorrência comum, esporádica ou excepcional ${ }^{19}$.

O considerável aumento dos isolamentos de Trichophyton tonsurans vem se tornando um fenômeno mundial. Trabalhos clássicos realizados até 1970, apontaram, o Microsporum audoinii e - Microsporum canis, como os agentes etiológicos mais freqüentemente isolados de Tinea capitis nos EUA $A^{5} 14152630$. No entanto, estudos mais recentes ${ }^{31}$ mostram que nas décadas de 1970 e 1990 houve um aumento excepcional de casos de Tinea capitis em áreas metropolitanas dos EUA; e apontam o Trichophyton tonsurans como responsável por $90 \%$ destes. Em consonância com esse estudo, Gupta e Summerbell ${ }^{14}$ relatam que entre os anos de 1985 e 1996, em Ontario (Canadá) a percentagem de Tinea capitis por T. tonsurans subiu de 9 para $76 \%$. Contrapondose a estes achados, as estatísticas dos Estados do Rio de Janeiro, Rio Grande do Sul, Espírito Santo e São Paulo, no Brasil; bem como do Norte da África e do Continente Europeu, mostram que - Microsporum canis, ainda, é o grande implicado nas Tinea capitis' 67122021 .

\section{MATERIAL E MÉTODOS}

As amostras analisadas consistiram de espécimes clínicos, oriundos de 2.297 pacientes portadores de lesões clínicas sugestivas de dermatofitoses, que procuraram o Serviço de Dermatologia do Hospital Universitário Walter Cantídio e o Centro Especializado de Micologia Médica, do Departamento de Patologia e Medicina Legal, da Faculdade de Medicina, da Universidade Federal do Ceará, durante o período de junho de 1996 a dezembro de 1998.

A etapa inicial do processamento laboratorial dos espécimes clínicos consistiu no exame direto, com hidróxido de potássio a $30 \%$ acrescido de tinta Parker, que permitiu o clareamento das escamas, proporcionando uma coloração azulada aos elementos fúngicos.

$O$ isolamento primário foi realizado simultaneamente ao exame direto. Alíquotas do material clínico foram repicadas em ágar Sabouraud modificado a $2 \%$ de glicose, ágar
Sabouraud acrescido de cloranfenicol e ágar Sabouraud com cloranfenicol e cicloeximida, sendo a seguir incubadas entre $25^{\circ} \mathrm{C}$ e $30^{\circ} \mathrm{C}$, durante um período de 15 a 20 dias, com observações diárias.

Após o aparecimento das colônias fúngicas, realizava-se a análise de suas características macroscópicas e microscópicas. A diferenciação macroscópica foi feita através do aspecto das colônias; enquanto o aspecto microscópico seguiu a visualização da presença ou ausência de estruturas de frutificação e ornamentação.

A identificação final, baseou-se em provas nutricionais e fisiológicas (teste da perfuração de pêlo in vitro, produção da urease, micromorfologia em lâmina e requerimentos vitamínicos).

A análise de associações da presença ou ausência de dermatófitos nos pacientes com as possíveis variáveis para existência de quadros de dermatofitose foi realizada através do teste 
de Fisher para variáveis dicotômicas; e o teste do Qui-quadrado de Pearson para as variáveis categorizadas. Com $\chi^{2}$, determinaram-se os níveis de significância das diferentes freqüências dos dados, sendo o valor considerado significativo somente quando a probabilidade (p) foi menor ou igual a 0,05.

\section{RESULTADOS}

Apartir das 2.297 amostras clínicas analisadas, $534(23,2 \%)$ mostraram-se positivas para dermatófitos. Estas amostras foram consideradas positivas quando apresentaram pesquisa direta e/ou cultura positiva. Desta feita, apenas $356(66,7 \%)$ amostras $(p \leq 0,05)$ tiveram pesquisa e cultura positivas, enquanto em 78 $(14,6 \%)$ detectou-se a presença de dermatófitos apenas na pesquisa direta; e nos 100 (18,7\%) casos restantes somente a cultura mostrou-se positiva com o isolamento de espécies de dermatófitos (Figura 1).

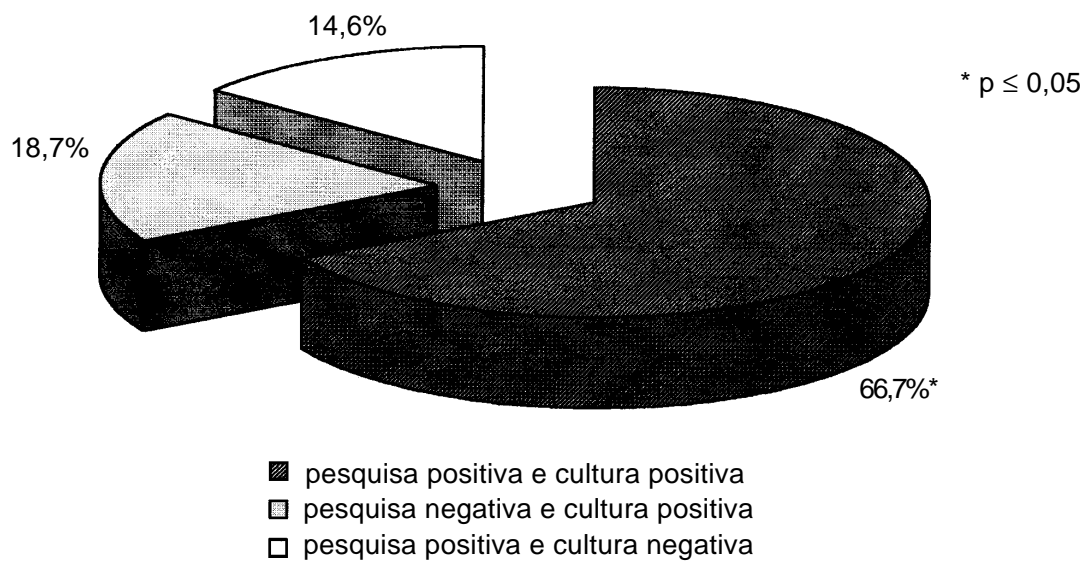

Figura 1 - Correlação de positividade dos exames direto e culturas em 534 amostras clínicas.

Quanto à ecologia, o grupo das espécies antropofílicas, representado pelo Trichophyton rubrum, Trichophyton tonsurans, Trichophyton mentagrophytes var. interdigitale, Epidermophyton floccosum e Trichophyton violaceum, mostrou predomínio absoluto, perfazendo $87,3 \%$ $(p \leq 0,05)$ dos isolamentos. As espécies zoofílicas (Microsporum canis, Trichophyton mentagrophytes var mentagrophytes e Trichophyton verrucosum) ficaram em segundo lugar com $12 \%$ e o grupo dos geofílicos respondeu por $0,6 \%$, sendo o Microsporum gypseum a única espécie isolada.

O sítio anatômico mais infectado foi o corpo (regiões de pele glabra) com 347 (65\%) casos. A partir de todas as amostras positivas para deratófitos $(n=534)$, encontraram-se $174(32,6 \%)$ na região inguinal, 25 (4,7\%) nos pés, $20(3,7 \%)$ na face, $9(1,7 \%)$ nas mãos e os $119(22,3 \%)$ casos restantes distribuídos nas regiões do tórax anterior e posterior, braços e pernas. As lesões no couro cabeludo ocorreram em (33\%)176 casos e as unhas foram infectadas $11(2 \%)$ vezes. Esses dados encontram-se ilustrados na Figura 2.

O T. rubrum foi a espécie mais freqüente $(49,6 \%$; $p \leq 0,05)$, seguido por T. tonsurans $(34,4 \%$; $\mathrm{p} \leq 0,05), M$. canis $(7 \%)$ e $T$. mentagrophytes $(6,2 \%)$. Das 28 cepas de T. mentagrophytes, 22 eram de T. mentagrophytes var mentagrophytes e 6 de T. mentagrophytes var interdigitale. As cepas de E. flocossum, M. gypseum, T. violaceum, $T$. verrucosum foram menos isoladas e juntas somaram apenas 13 isolamentos (Figura 3 ).

Correlacionando-se as espécies isoladas com os respectivos sítios anatômicos infectados, observou-se que o $T$. tonsurans foi isolado em $73,9 \%(p \leq 0,01)$ das lesões do couro cabeludo. Por outro lado, o T. rubrum esteve presente em $72,8 \%$ e $77,7 \%$, $(p \leq 0,01)$, das lesões do corpo e unhas, respectivamente. A relação em ordem 


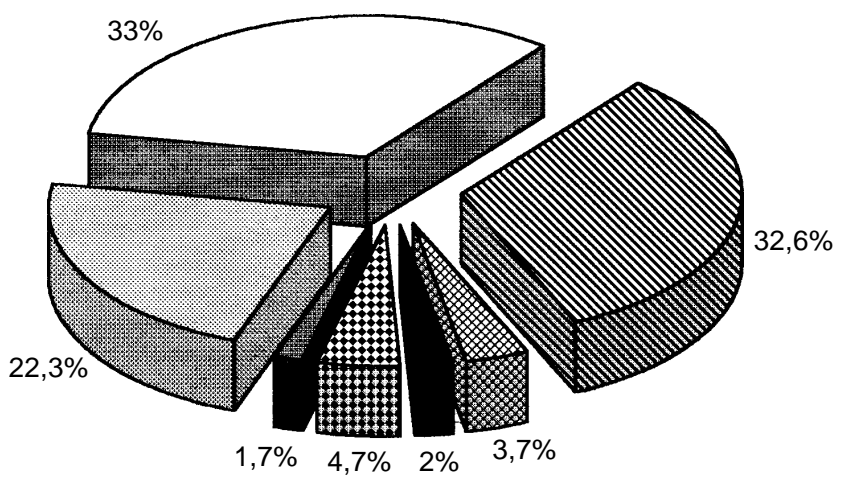

\begin{tabular}{ll}
\hline couro cabeludo & região inguinal \\
face & unhas \\
pés & mãos
\end{tabular}

Figura 2 - Sítios anatômicos das dermatofitoses em Fortaleza, CE.

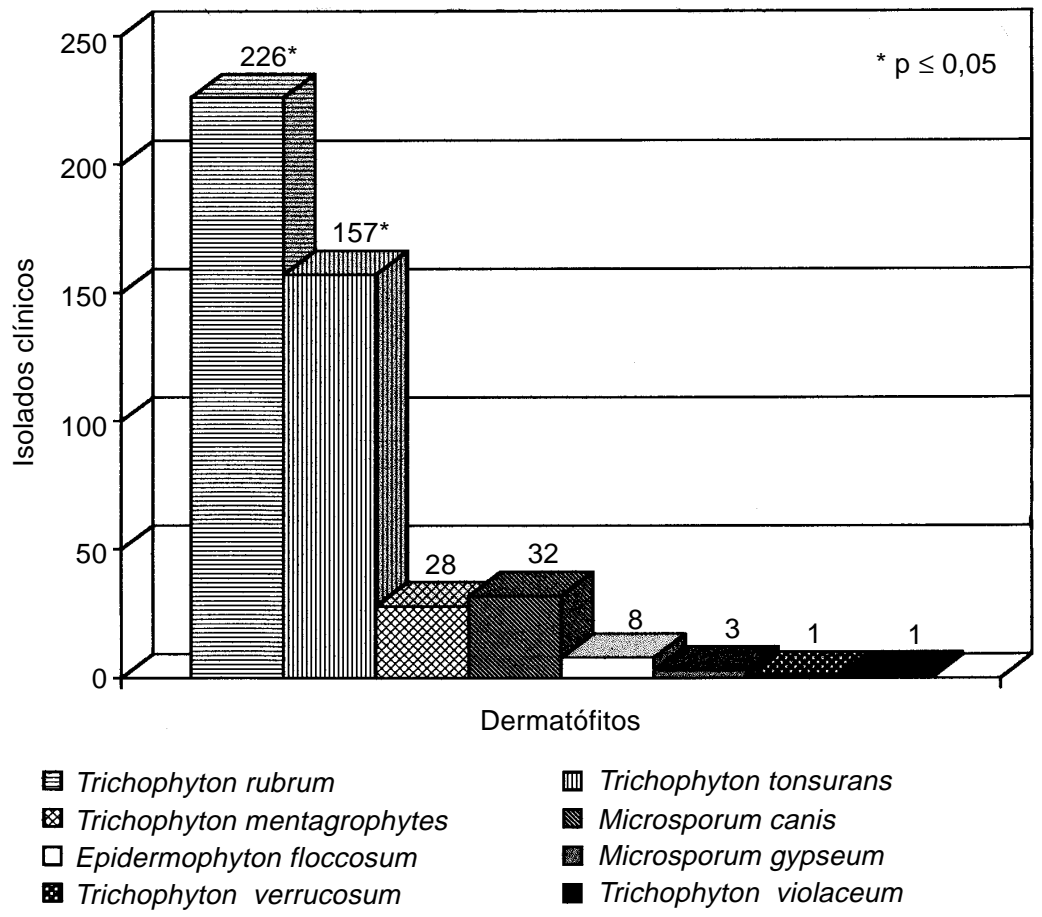

Figura 3 - Prevalência das espécies de dermatófitos isolados em 456 culturas. 
de freqüência das espécies isoladas em cada um desses sítios anatômicos encontra-se expressa na Figura 4.

Em relação à faixa etária, os indivíduos mais acometidos foram os compreendidos na faixa etária de $0-10$ anos (132 casos; $p \leq 0,05)$, seguido de $10-20$ anos (88 casos). Foi possível ainda, relatar casos de dermatofitoses em 56 pacientes maiores de 50 anos. Entretanto, em 97 casos não foi possível correlacionar esse dado, pois os pacientes omitiram a idade quando inquiridos (Figura 5).
Numa relação estreita entre a faixa etária e a localização topográfica das lesões, observamos que nos pacientes de $0-10$ anos, o couro cabeludo foi o local de predição das dermatofitoses $(87 \% ; p \leq 0,05)$. As lesões na região inguinal foram as mais incidentes nos pacientes de 11-20 anos e nos acima de 50 anos com $41 \%$ e $46,5 \%$ respectivamente. A Tabela 1 correlaciona os sítios anatômicos acometidos com a idade dos pacientes.

No tocante ao sexo dos pacientes, o sexo feminino foi o mais acometido com $305(57,1 \%)$ casos ( $p \leq 0,05)$ e o masculino com 229 (42,9\%).

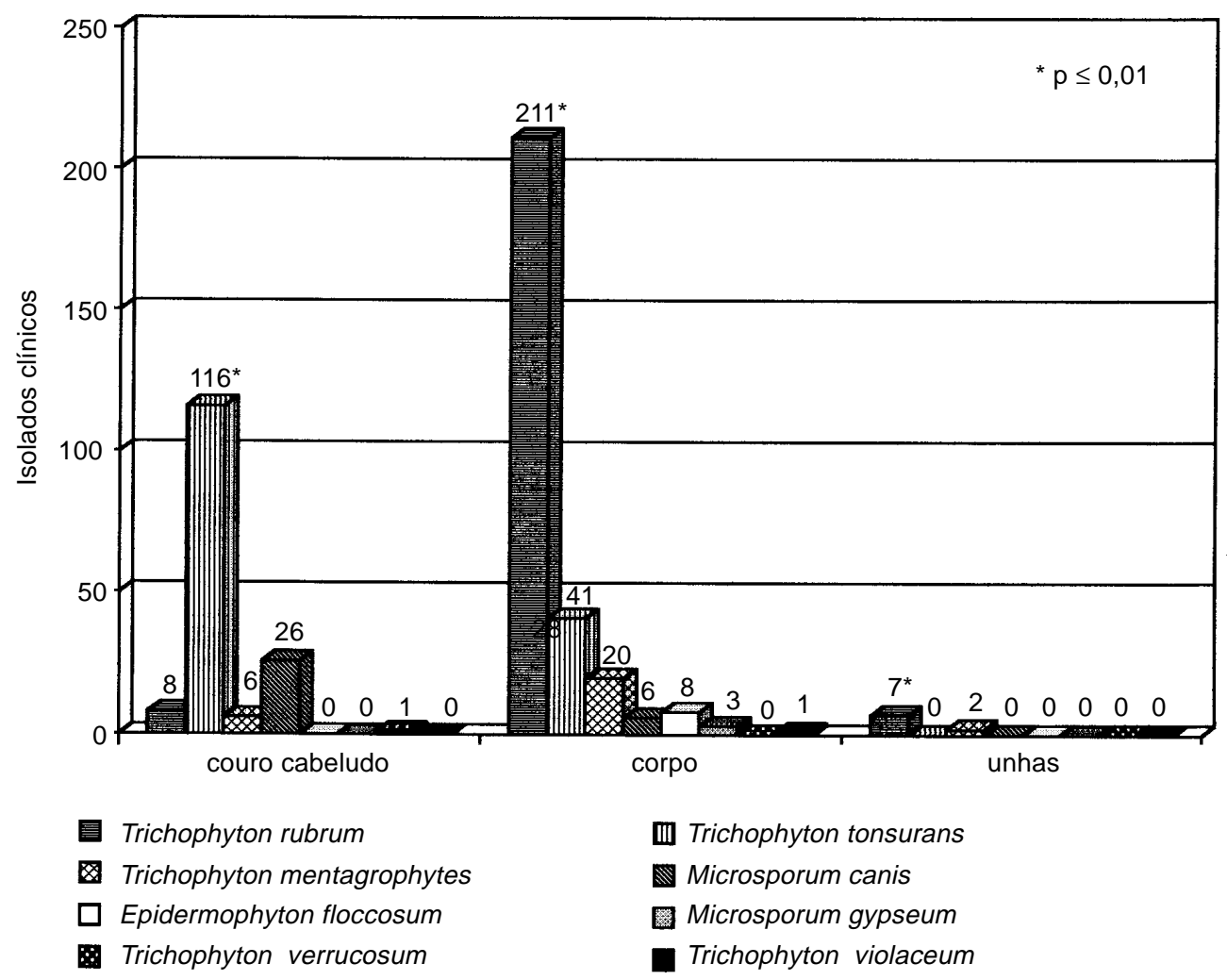

Figura 4 - Distribuição das espécies de dermatófitos segundo o sítio anatômico acometido em 456 isolamentos clínicos. 


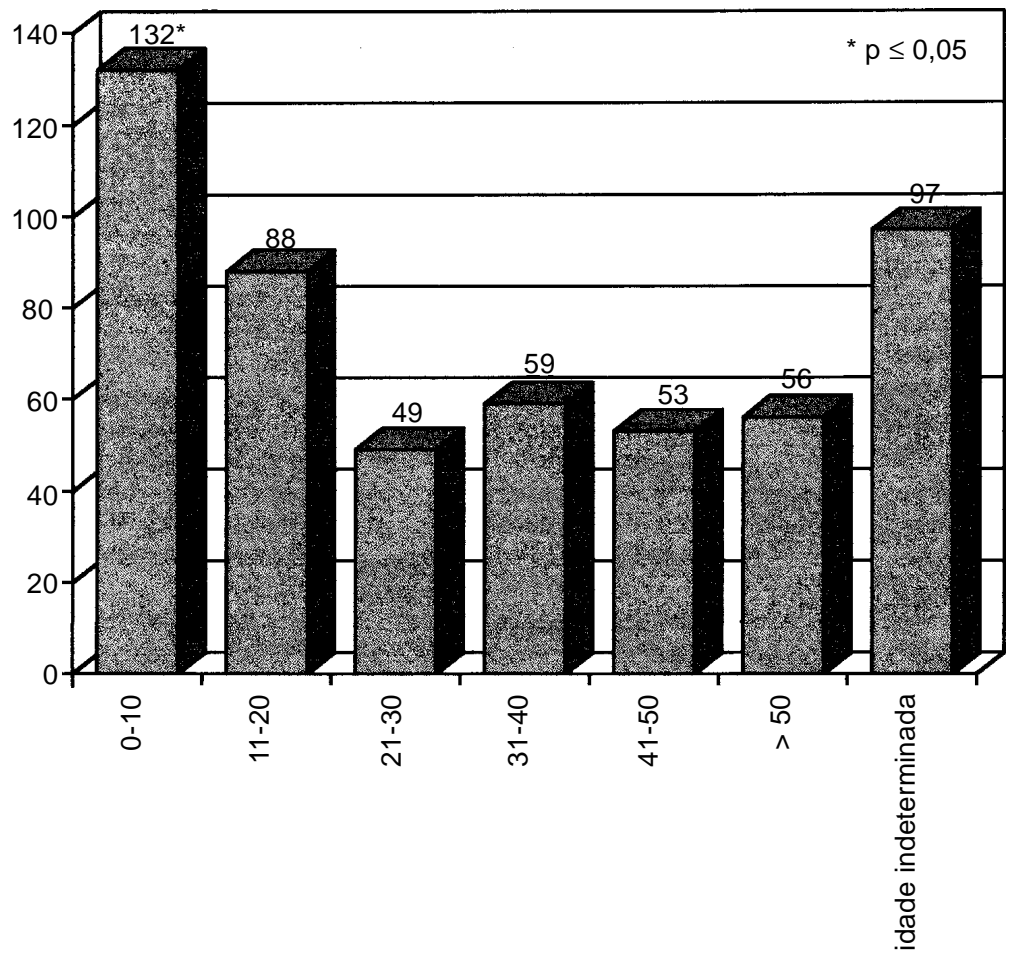

Figura 5 - Distribuição das dermatofitoses por faixa etária em 534 pacientes.

Tabela 1 - Faixas etárias relacionadas com sítios anatômico das dermatofitoses em Fortaleza, CE.

\begin{tabular}{lcccccccc}
\hline Faixa etária & \multicolumn{8}{c}{ Sítios anatômicos } \\
\cline { 2 - 9 } (ano) & pés & mãos & região inguinal & face & unhas & couro cabeludo & outros & Total \\
\hline $0-10$ & 1 & $\varnothing$ & 4 & 4 & 1 & $115^{*}$ & 7 & 132 \\
$11-20$ & 2 & $\varnothing$ & 36 & 10 & $\varnothing$ & 27 & 13 & 88 \\
$21-30$ & 4 & $\varnothing$ & 21 & 2 & 1 & 7 & 14 & 49 \\
$31-40$ & 6 & 2 & 28 & 4 & 1 & 1 & 17 & 59 \\
$41-50$ & 7 & $\varnothing$ & 33 & $\varnothing$ & 2 & $\varnothing$ & 11 & 53 \\
$>50$ & 3 & $\varnothing$ & 26 & 3 & $\varnothing$ & 4 & 20 & 56 \\
\hline
\end{tabular}

$\varnothing$ nenhum caso encontrado.

${ }^{*} \mathrm{p} \leq 0,05$

\section{DISCUSSÃO}

Calcula-se com base numa prevalência estimada que 10 a $15 \%$ da população mundial, pode ser infectada pelos dermatófitos no decorrer de suas vidas 2329 . A presente pesquisa revelou um índice de $23,2 \%$ de dermatofitoses no grupo populacional estudado. Embora esse dado seja superior ao das estatísticas mundiais, ele ainda pode não corresponder exatamente a magnitude do problema em nosso meio, uma vez que no Brasil as dermatofitoses não estão enquadradas entre as doenças de notificação compulsória.
Dentre os casos confirmados laboratorialmente, $34 \%$ mostraram-se positivos apenas ao exame direto ou na cultura. Como possíveis explicações ao achado da combinação de exames diretos positivos com cultura negativas, pode-se pensar na escassez de elementos fúngicos viáveis, nas amostras, e na presença exclusiva de estruturas fúngicas inviáveis, devido ao uso prévio de medicamentos antifúngicos. Apesar da evidente importância da positividade do exame direto, principalmente em ocasiões nas quais a cultura 
se revelara infrutífera, o uso desse método como único indicador do diagnóstico laboratorial é desaconselhado, pois um exame direto negativo não descarta a possibilidade de uma dermatofitose, especialmente nas infecções onde o $M$. canis é o agente causal, já que esta espécie parece necessitar de uma maior quantificação das estruturas fúngicas, presentes na amostra clínica, para que seja detectada ao exame direto.

No tocante ao padrão ecológico dos dermatófitos, constatou-se um predomínio absoluto dos fungos antropofílicos, frente aos dermatófitos zoofílicos e geofílicos. Tais resultados contrastam com pesquisas realizadas em regiões rurais, onde o isolamento de dermatófitos zoofílicos sobrepuja os demais grupos, caracterizando o contato direto do homem com diferentes espécies animais $^{1927}$. O envolvimento de espécies zoofílicas em apenas $12 \%$ dos casos está em consonância com os estudos realizados por Pinheiro et $\mathrm{al}^{25}$, que estudaram a ligação entre as dermatofitoses humanas e o convívio com animais, tendo concluído que a estreita ligação do homem com animais de estimação, como cães e gatos, é pouco representativo como fator condicionante da ocorrência de dermatofitoses no meio urbano. Por conseguinte, a predominância das dermatofitoses antropofílicas representa o perfil provável da flora dermatofítica urbana.

Através deste estudo, foi possível caracterizar as espécies de dermatófitos mais envolvidas nas dermatofitoses do nosso meio, observando que o T. rubrum é a espécie mais cosmopolita desse grupo fúngico, tendo sido isolado em quase metade dos casos, seguido pelo $T$. tonsurans, $M$. canis, T. mentagrophytes e E. flocossum. O M. gypseum teve ocorrência bem menos freqüente, enquanto que $T$. verrucosum e $T$. violaceum foram isolados apenas excepcionalmente.

O sítio anatômico mais infectado foi o corpo (regiões de pele glabra) especialmente a região inguinal, provavelmente devido a maior umidade e o uso de roupas justas que promovem, em última análise, a maceração da pele em tais locais. As lesões no couro cabeludo vieram em segundo lugar, diferindo da realidade do Rio de Janeiro e Manaus, onde os pés e o couro cabeludo, respectivamente, são os alvos mais comuns dos dermatófitos ${ }^{611}$.

Nas infecções do couro cabeludo, observou-se que houve predomínio absoluto do T. tonsurans, dado este semelhante aos encontrados em Manaus, Brasília e região amazônica ocidental ${ }^{11} 1724$ 28, onde este dermatófito é o mais envolvido na Tinea capitis. A distribuição deste fungo parece obedecer sua melhor adaptação às condições de determinados ecossistemas. De fato, o $T$. tonsurans vem se mostrando bastante adaptado à temperatura e umidade relativas elevadas das regiões Norte e Nordeste do Brasil, diferindo substancialmente do clima seco e umidade relativa do ar sempre em níveis baixos encontrados, nos Estados do Sul e Sudeste ${ }^{28}$, onde este fungo é considerado um dermatófito de importação, isto é, um microrganismo trazido por imigrantes, não fazendo parte da flora dermatofítica própria do lugar ${ }^{4}$. No entanto, se contrapondo a esses números, as estatísticas dos Estados do Rio de Janeiro, Rio Grande do Sul, Espírito Santo e São Paulo, no Brasil, bem como o Norte da África e o Continente Europeu mostram que o M. canis, ainda, é o grande incriminado na Tinea capitis, sendo responsabilizado por $67 \%$ dos casos 620212229 . Neste estudo, o $M$. canis teve uma incidência relativamente baixa, talvez por não se adaptar bem às nossas condições locais.

Em adição, o T. tonsurans mostrou em isolamentos primários características fenotípicas bastante diferentes das relatadas na literatura clássica, uma vez que em algumas cepas visualizaram-se apenas clamidoconídios em cadeias, situação essa que pode levar alguns micologistas a confundirem o T. tonsurans com o T. verrucossum, já que esse achado micromorfológico caracteriza classicamente o $T$. verrucosum. Entretanto em testes secundários, tais como: necessidades nutricionais, a identificação final demonstrou tratar-se de T. tonsurans.

Das espécies causadoras de Tinea cruris, Tinea pedis, Tinea manum e Tinea unguium, o T. rubrum foi o mais prevalente, reforçando os dados da literatura mundial que aponta esse fungo como o mais cosmopolita e implicado na gênese das dermatofitoses 36121720 .

A casuística desta pesquisa apontou uma baixa incidência da Tinea pedis, o que pode ser explicado pelo hábito das populações de clima quente em usar sapatos abertos, diferentemente do que ocorre em regiões mais frias, onde o uso de calçados fechados torna-se obrigatório, acarretando um ambiente úmido, propício para o desenvolvimento de dermatófitos.

Dados relativos a incidência de Tinea unguium são conflitantes, variando de $2 \%$ nos EUA a $13 \%$ na população da Finlândia ${ }^{9}$. Comparativamente a essas estatísticas, houve 
uma incidência de $2 \%$ de onicomicoses dermatofíticas nas unhas dos pés na população estudada. Possivelmente, os dados apresentados podem ter sido prejudicados pelo diagnóstico dado apenas pela clínica médica, ou mesmo, pela inadequada colheita do material ungueal, visto que, os elementos fúngicos viáveis localizam-se, quase sempre, na porção proximal da unha, local esse de difícil acesso, tornando o ato da colheita bastante doloroso e rejeitado por alguns pacientes.

No que se refere à distribuição das dermatofitoses por faixas etárias, observou-se que os pacientes entre $0-10$ anos de idade foram os mais acometidos, seguidos pelos de 11-20 anos. A predileção dessas doenças por crianças, pode ser explicada pelo fato destas estarem mais expostas a fatores de risco, tais como: precários hábitos higiênicos e aglomerações em colégios e creches; embora a literatura cite que contato direto das crianças com animais domésticos e brincadeiras com areia também contribuam para uma maior ocorrência de dermatofitoses nesse grupo populacional ${ }^{26}$. No entanto, nossos dados aliados a de outros autores ${ }^{25}$ comprovam que esses fatores são minoritários na história natural da doença.

Estudos realizados no Rio Grande do $\mathrm{Su}^{20} \mathrm{e}$ no Distrito Federal ${ }^{17}{ }^{28}$, diferentemente da casuística deste trabalho, mostram que a faixa etária mais atingida é a compreendida entre 20-29 anos. A ocorrência de $10,4 \%$ das dermatofitoses em pacientes com mais de 50 anos de idade é um dado bastante relevante, visto que a literatura considera a ocorrência dessa patologia nesse grupo específico, como rara ou excepcional.

A observação da maior incidência de Tinea capitis por T. tonsurans, em determinadas regiões, é de fundamental importância no que se refere a ecologia, epidemiologia e ao tratamento das dermatofitoses, visto que a literatura especializada relata o $M$. canis como o dermatófito mais freqüentemente isolado em casos de Tinea capitis. Por outro lado, ao se observar uma maior incidência de Tinea capitis, por T. tonsurans novas situações epidemiológicas são afloradas, como por exemplo, uma transmissão inter-humana mais eficiente deste dermatófito, situação essa respaldada por vários relatos de surtos epidêmicos, onde o T. tonsurans é o agente causal. Além do mais, devido a melhor adaptação desse microrganismo ao hospedeiro humano, evidencia-se na literatura uma escassez de casos de Tinea capitis descritos em pacientes adultos e imunocompetentes. Por último, as avaliações das medidas terapêuticas nas Tineas capitis devem ser mais minuciosamente avaliadas, visto que há relatos de casos de dermatofitoses por espécies antropofílicas, nas quais a resposta terapêutica não é tão eficiente. Sendo assim, é de fundamental importância, constantes estudos epidemiológicos das dermatofitoses, visando auxiliar clínicos e dermatologistas na melhor conduta terapêutica dessas dermatomicoses em cada região.

\section{REFERÊNCIAS BIBLIOGRÁFICAS}

1. Ajello L. Natural history of the dermatophytes and related fungi. Mycopathologia 53:93-110, 1974.

2. Azulay RD, Monteiro E, Azulay E. Micoses superficiais, sua freqüência no Rio de Janeiro. Anais Brasileiros de Dermatologia 42:91-96, 1967.

3. Babel DE. How to identify fungi. Journal of the Academy of Dermatology 31: 108-111, 1994.

4. Bassanesi MC, Priebe A, Severo LC. Dermatofitose por Trichophyton tonsurans no Rio Grande do Sul. Arquivos brasileiros de Medicina 68:181-183, 1994.

5. Benavides MI, Moncada X, Olate C, Vogel M, Rodriguez B. Diagnostico de laboratorio de las dermatofitoses: experiencia de 10 años en el area occidente de Santiago. Revista Médica de Chile 119:1029-1032, 1991.

6. Costa EF, Wanke B, Martins ECS. Micoses superficiais e cutâneas: estudo comparativo entre duas populações - Rio de janeiro (RJ) e Aracaju (SE). Anais Brasileiros de Dermatologia 66:119-122, 1991.
7. Crozier WJ. Keratinophilic Dermatophytes. Medical Journal of Australia 2:200-206, 1960.

8. Diaz MC, Salamanca L, Piontelli E. Dermatofitosis: un problema del passado, un desafio del presente. Adelantos en Microbiologia e Enfermidades Infecciosas 3:212-273, 1984.

9. Elewski BE. Onichomycosis: pathogenesis, diagnosis, and management. Clinical Microbiology Reviews 11:415429, 1998.

10. Frieden IJ, Howard R. Tinea capitis: epidemiology, diagnosis, treatment, and control. Journal of The American Academy of Dermatology 31:42-46, 1994.

11. Furtado MSS, Ihara LT, Maroja MF, José JINS, Castrillón AL. Dermatofitose na cidade de Manaus. Anais Brasileiros de Dermatologia 62:195-196, 1987.

12. Gonçalves HMG, Mapurunga ACP, Queiroz JAN, Diógenes MJN. Dermatofitoses: principais agentes etiológicos em Fortaleza. Anais Brasileiros de Dermatologia 64:26-27, 1989. 
13. Greer DL. An overview of commom dermatophytes. Journal of the American Academy of Dermatology 31:112-116, 1994.

14. Gupta AK, Summerbell RC. Increased incidence of Trichophyton tonsurans Tinea capitis in Ontario, Canadá between 1985 and 1996. Medical Mycology 36:55-60, 1997.

15 Jahangir M, Hussain I, Khurshid K, Haroon TS. A clinico-etiologic correlation in Tinea capitis. International Journal of Dermatology 38:275-278, 1999

16 Lacaz CS, Porto E, Martins JEC. Micologia médica. Editora Sarvier, 8a edição, São Paulo, 1991.

17. Leite RMS, Fogaça SA, Santos, MG, Maia, HCA. Dermatofitose em Brasília. Hfa Publicação Técnica e Científica 5:29-42, 1990.

18. Lima EO, Oliveira NMC, Guerra MFL, Pontes ZBVS, Carvalho MFFP, Santos JP. Freqüência de dermatofitoses em João Pessoa- Paraíba- Brasil. Anais Brasileiros de Dermatologia 74:127-132, 1999.

19. Londero AT, Ramos CD. Agentes de dermatofitoses humana no interior do Estado do Rio Grande do Sul no período de 1960-1987. Anais Brasileiros de Dermatologia 64:161-164, 1989.

20. Lopes JO, Alves SH, Benevenga JP. Dermatofitoses humanas no interior do Rio Grande do Sul no período de 1988-1992. Revista do Instituto de Medicina Tropical de São Paulo 36:115-119, 1994.

21. Mattêde MGS, Coelho CC, Mattêde AF, Perin FC, Palhano Júnior L. Etiologia das dermatofitoses em Vitória (ES). Anais Brasileiros de Dermatologia 61:177-182, 1986.

22. Mezzari A. Frequency of dermatophytes in the metropolitan area of Porto Alegre, RS, Brazil. Revista do Instituto de Medicina Tropical de São Paulo 40:71-76, 1998.

23. Murray PR, Kobayashi GS, Pfaller MA, Rosenthal KS. Superficial, cutaneous and subcutaneous mycosis.
In: Microbiology medical. $2^{\text {a }}$ edition, Mosby, p. 404-437, 1994.

24 Pecher SA, Castro GB, Borras MRL. Prevalência de micoses superficiais em escolares de localidades da região da Amazônia Ocidental (fronteira BrasilColômbia). Anais Brasileiros de Dermatologia 57:13-18, 1982.

25. Pinheiro AQ, Moreira JLB, Sidrim JJC. Dermatofitoses no meio urbano e a coexistência do homem com cães e gatos. Revista da Sociedade Brasileira de Medicina Tropical 30:287-294, 1997.

26. Proença NG. Dermatofitose na infância: aspectos clínicos e Terapêuticos. Revista Paulista de Medicina 108:279284, 1991.

27. Raza A. Ecology and epidemiology of dermatophyte infections. Journal of Academy of Dermatology 31:108110. 1994

28. Reis CMS, Gaspar APA, Gaspar NK, Leite RMS. Estudo da flora dermatofítica na população do Distrito Federal. Anais Brasileiros de Dermatologia 67:103-111, 1992.

29. Sidrim JJC, Moreira JLB. Fundamentos Clínicos e Laboratoriais da Micologia Médica. Editora Guanabara Koogan, São Paulo, 1999.

30. Weitzman I, Chin NX, Kunjukunju N, Della Latta P. A survey of dermatophytes isolated from patients in the United States from 1993 to 1995 . Journal of the American Academy of Dermatology 39:255-261, 1998.

31. Wilmington M, Aly R, Frieden IJ. Trichophyton tonsurans Tinea capitis in San Francisco Bay area: increased infection demonstrated in 20-year survey of fungal infections from 1974 to 1994 . Journal of Medical and Veterinary Mycology 34:285-287, 1996.

32. Zaias N, Rebell G. Chronic dermatophytosis syndrome due to Trichophyton rubrum. International Journal of Dermatology 35:614-617, 1996. 